\title{
Isolation of Microcrystalline Cellulose (MCC) from Oil Palm Frond as Potential Natural Filler for PVA-LiClO 4 Polymer Electrolyte
}

\author{
M. Hazwan Hussin ${ }^{1, *}$, Nurhanina Ayu Husin ${ }^{1}$, Ibrahim Bello ${ }^{1}$, Nurmaizatulhana Othman ${ }^{1}$, Mohamad \\ Abu Bakar ${ }^{1}$, M.K. Mohamad Haafiz, \\ ${ }^{1}$ Materials Technology Research Group (MaTReC), School of Chemical Sciences, Universiti Sains \\ Malaysia, 11800 Minden, Penang, Malaysia. \\ ${ }^{2}$ School of Industrial Technology, Universiti Sains Malaysia, 11800 Minden, Penang, Malaysia. \\ *E-mail: $\underline{\text { mhh@usm.my; mhh.usm@gmail.com }}$
}

doi: $10.20964 / 2018.04 .06$

Received: 6 December 2017 / Accepted: 22 January 2018 / Published: 6 March 2018

\begin{abstract}
In this study, microcrystalline cellulose (MCC) was extracted from organosolv oil palm fronds (OPF) pulp via acid hydrolysis method. The isolated OPF-MCC were characterized using complementary analysis such as FTIR, CP/MAS ${ }^{13} \mathrm{C}$ NMR, XRD, GPC, TGA, DSC, SEM and $\mathrm{N}_{2}$-BET. It was found that the isolated OPFMCC was identified as cellulose type I polymorph with high crystallinity index than $\alpha$-cellulose $\left(\mathrm{CrI}_{\mathrm{OPF} \text { MCC }}: 76.38 \%>C r I_{\alpha \text {-cellulose }}: 73.37 \%\right)$. The obtained OPFMCC was then incorporated with PVA-LiClO 4 at different $\mathrm{LiClO}_{4}$ loading $(0,5,10,15,20 \%)$ through solution casting technique to produce biodegradable polymer electrolytes of OPFMCC-PVA-LiClO ${ }_{4}$ The fabricated films were further analyzed using electrochemical impedance spectroscopy (EIS) and cyclic voltammetry $(\mathrm{CV})$. It interesting to note that, a maximum conductivity was found to be $1.88 \times 10^{-4} \mathrm{~S}$ $\mathrm{cm}^{-1}$ for OPF MCC-PVA-20 \% $\mathrm{LiClO}_{4}$ with electrochemical stability window potential around $1.9 \mathrm{~V}$.
\end{abstract}

Keywords: Oil palm frond; microcrystalline cellulose; polymer electrolytes.

\section{$\underline{\text { FULL TEXT }}$}

(C) 2018 The Authors. Published by ESG (www.electrochemsci.org). This article is an open access article distributed under the terms and conditions of the Creative Commons Attribution license (http://creativecommons.org/licenses/by/4.0/). 